\title{
КЛИНИЧЕСКИЙ СЛУЧАЙ РЕДКОЙ МОЗАИЧНОЙ ФОРМЫ СИНДРОМА ШЕРЕШЕВСКОГО-ТЕРНЕРА
}

\author{
Т.Б. Квашнина-Самарина, А.Н. Коншина, Т.А. Ткачева, Н.В. Иеронова, С.Р. Кожемякина \\ ДГП 131 г. Москвы
}

ВВЕДЕНИЕ: Синдром Шерешевского-Тернера (в дальнейшем синдром Ш-Т) обусловлен полной или частичной моносомией по Х-хромосоме, представленной во всех клетках организма или же в части клеток. Это заболевание встречается с частотой 1:2000-1:2500 новорожденных девочек.

Применение методов хромосомного зондирования, позволяющего выявить более детальные структурные изменения хромосом, показало, что чистая 45,X- моносомия встречается только у 50-60\% больных, вторым по частоте встречаемости является мозаицизм 45,X/46,XX, выявляемый у $14 \%$ пациентов с синдромом Ш-Т. К более редким формам синдрома по данным ФГУ ЭНЦ, 2006 относится кариотип 45,X/47,XXX - 1\%. Клинические проявления синдрома Ш-Т чрезвычайно разнообразны, и степень их выраженности крайне вариабельна. К основным и наиболее постоянным клиническим проявлениям синдрома относятся задержка роста, первичный гипогонадизм и целый ряд врожденных аномалий: крыловидные складки шеи, низкий рост волос, птоз, эпикант, высокое готическое небо, ротированные ушные раковины. У пациенток с синдромом Ш-Т часто встречаются такие заболевания как аутоиммунный тиреоидит и целиакия.

PEЗЮМЕ: В отделении эндокринологии по ЗАО наблюдается ребенок А. девочка, 10 лет с диагнозом: Задержка физического развития не связанная с дефицитом гормона роста, на фоне мозаичной формы синдрома Шерешевского-Тернера (mos 47,XXX /45,X). Гипергонадотропный гипогонадизм, обусловленный основным диагнозом. Хронический аутоиммунный тиреоидит, фаза субкомпенсации.

ОПИСАНИЕ КЛИНИЧЕСКОГО СЛУЧАЯ: Ребенок наблюдается У эндокринолога с мая 2017 г. в связи с жалобами на задержку физического развития в сравнении со сверстниками. В июне 2017 г. был выявлен хронический аутоиммунный тиреоидит. В апреле 2018 г. начата заместительная гормональная терапия Levothyroxini natrii 25 мкг/сут с последующей коррекцией дозы до 62.5 мкг/сут на момент марта 2021. Со слов, препарат принимается регулярно.

\section{ДИНАМИКА РОСТА:}

С мая 2017 г. по февраль 2018 (9 мес) - 4.5 см,

с февраля 2018 по апрель 2019 (1 год 2 мес) - 4.5 см

с апреля 2019 по июнь 2020 (1 год 2 мес) -6.5 см

с июня 2020 по октябрь 2020 (4 мес) - без динамики

с декабря 2020 по февраль 2021 (на терапии за 2 мес) + 3 см

Данные объективного осмотра на момент мая 2017 (6 лет 8 мес):

Рост - 109 см, вес - 17 кг SDS роста - 1.8 (физическое развитие низкое, на 5 лет) ИМТ $14 \mathrm{~S}$ пов. тела. $0.7 \mathrm{M}^{2}$. В объективном статусе без значимых патологий.

При дообследовании был выявлен хронический аутоиммунный тиреоидит, без нарушения функции щитовидной железы.

Назначен контрольный осмотр в августе-сентябре

2017 г., на прием пришли в феврале 2018 г..

Рост -113.5 см, вес - 19.5 кг SDS роста -1.6

ИМТ $16.1 \mathrm{~S}$ пов. тела. $0.8 \mathrm{M}^{2}$

Было назначено повторное обследование, которое прошли в октябре 2018 г., по результатам был выявлен субклинический гипотиреоз в связи с чем назначена заместительная гормональная терапия Levothyroxini natrii 25 мкг/сут. Также исследовался уровень соматомедина - C : 96 (56.9-277), который оказался в норме. С декабря 2018 г. по апрель 2019 г. на прием не обращались. В апреле 2019 г. было назначено повторное дообследование, также 


\section{СБОРНИК ТЕЗИСОВ}

XVII Российская научно-практическая конференция детских эндокринологов «Достижения науки в практику детского эндокринолога»

направлялась на консультацию к генетику в МДГКБ №1, на консультацию обратились в октябре 2019 при дообследовании был выявлен синдром Шерешевского-Тернера мозаичная форма (Кариотип: $\operatorname{mos} 47, \mathrm{XXX} / 45, \mathrm{X}$ - обнаружено два клона клеток : с тремя хромосомами X и одной хромосомой X). Осенью 2019 г. также дважды перенесла гнойный переостит нижней челюсти слева.

Данные осмотра от 11.2019 (9 лет 2 мес):

Рост 120 см. вес 22.6 ИМТ 15.7, SDS роста - 2.0 (физическое развитие низкое для возраста ниже $3 \%$, но среднее - 50-75\% по перцентильным таблицам для девочек с С-мом Ш-Т). В объективном статусе без патологии.

Учитывая полученные данные анализов была скорректирована доза получаемой заместительной терапии, также ребенок был направлен на дополнительные дообследования с целью исключения сопутствующей патологии, характерной для синдрома Ш-Т, чего обнаружено не было.

В дальнейшем в связи с неблагоприятной эпидемиологической ситуацией долго на прием не обращались, на прием обратились в июне 2020.

Данные объективного осмотра от 06.2020:

Ребенок 9 лет 9 мес. Рост 124.5 см, вес 23 кг

(физическое развитие - менее $3 \%$ - низкое,

но средне - 50-75\% по нормам для девочек с (-мом Ш-Т)

SDS роста - 1.8 ИМТ 14.8

В дальнейшем на приеме в октябре 2020 г., по просьбе матери, ребенок был направлен на дообследование в МДГКБ №1, где девочка прошла полное обследование и была рекомендована повторная госпитализация в 12 лет для решения вопроса о начале заместительной гормональной терапии эстрогенами.

MPТ гипофиза (от октября 2020) - Данных за патологию гипофиза нет Гормоны: эстрадиол 15.83, ЛГ 32.5, св Т4 12.85 (11-22), ТТГ 5.79 (0.35- 4.2), ФСГ 113.44. Выявлен гипергонадотропный гипогонадизм на фоне основного заболевания. Осуществлялась коррекция получаемой заместительной гормональной терапии.

Самостоятельно в декабре 2020 г. родители с ребенком обратились в ФГБУ НМИЦ эндокринологии для решения вопроса о пробной инициации терапии соматропином из нефедерального бюджета. С 07.12. 2020 начата терапия Соматропином (Омнитропом) в дозе 0.045 мг/кг /сут (1.1 мг/сут).

Данные объективного осмотра от 02.2021:

Рост 127.2 см, вес 26 кг (физическое развитие - менее $3 \%$ - низкое, но средне - 50-75\% по нормам для девочек с (-мом Ш-Т) SDS роста - 1.87 ИМТ 16.1

Основной диагноз: Задержка физического развития не связанная с дефицитом гормона роста, на фоне мозаичной формы синдрома Шерешевского-Тернера (mos 47,XXX /45,X). Гипергонадотропный гипогонадизм на фоне основного заболевания. Хронический аутоиммунный тиреоидит, медикаментозная субкомпенсация.При повторном обследовании выявлен субклинический гипотиреоз, в связи с чем осуществлена коррекция получаемой заместительной терапии.

Осуществлена коррекция получаемой заместительной гормональной терапии. В настоящий момент, ребенок находится на терапии гормоном роста и гормоном щитовидной железы: Соматропин по 1.1 мг/сут п/к на ночь (по рекомендации ЭНЦ) и Levothyroxini natrii 62.5 мкг/сут 1 раз в день, за 30 мин до завтрака - постоянно. Динамика роста на терапии + 3 см за 5 мес. Рекомендован повторный осмотр у эндокринолога с целью контроля тиреоидного профиля на увеличенной дозе препарата через 2 мес.

ЗАКЛЮчЕНИЕ: Описанный выше случай редкой мозаичной форма синдрома Шерешевского-Тернера наглядно демонстрирует необходимость в настороженности по данной патологии у девочек, обращающихся для дообследования с жалобами на задержку физического развития. Также в отдельных случаях назначение терапии гормоном роста, может быть эффективно. 